\title{
La arquitectura, el espacio público y el derecho a la ciudad Entre lo físico y lo vivencial
}

\author{
Architecture, public space and the right to the city. Between the physical and the experiential
}

\section{Erika Tatiana Ayala-García}

Universidad Francisco de Paula Santander (Colombia)

Facultad de Educación, Artes y Humanidades, Programa de Arquitectura,

Grupo de Investigación TAR_GET

Ayala-García, E. T. (202I). La arquitectura, el espacio público y el derecho a la ciudad. Entre lo físico y lo vivencial. Revista de Arquitectura, (Bogotá) 23(2), 36-46. https://doi.org/10.14718/RevArq.2021.3286

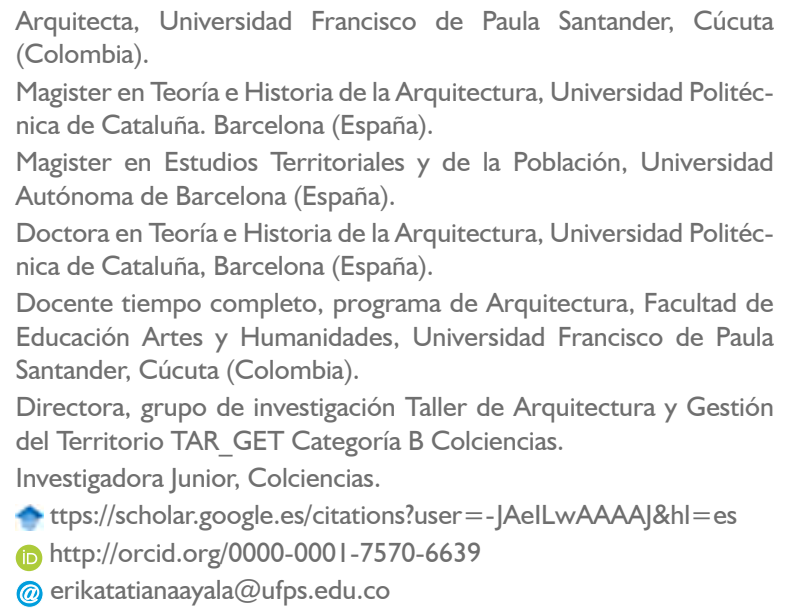

\section{Introducción}

\section{Resumen}

Se analiza la plaza como elemento articulador y dinamizador del espacio público, a partir del estudio de sus características físicas y vivenciales, así como de las dimensiones física, social e histórica, con el fin de determinar su importancia dentro del desarrollo social y la planificación urbana. Para ello, se utiliza una metodología de revisión documental o bibliográfica interdisciplinar, bajo la técnica de análisis de contenido centrada en la plaza, a partir de categorías o temáticas de estudio como ciudad, urbanismo y planeación territorial, a través de las cuales se desarrollaron los resultados mediante dos componentes teóricos: la dimensión física del espacio público, y la plaza desde lo físico y lo vivencial. Como hallazgo relevante, se reconoce la importancia de la plaza en la construcción y el fortalecimiento de la ciudadanía bajo preceptos sociales y antropológicos que promueven la identidad, el arraigo, y el sentido de pertenencia. Así mismo, se determina la importancia de diagnosticar la calidad de los ambientes físicos de la ciudad a partir de su forma y su función.

Palabras clave: habitabilidad; historia; planificación urbana; plaza, sentido de pertenencia

\begin{abstract}
The square is analyzed as an articulating and energizing element of public space, based on the study of its physical and experiential characteristics and its physical, social and historical dimensions, in order to determine its importance within social development and urban planning. For this purpose, an interdisciplinary documentary or bibliographic review methodology is used, under the technique of content analysis focused on the square, based on categories or study topics such as city, urbanism and territorial planning, through which the results were developed utilizing two theoretical components: the physical dimension of public space and the square from the physical and experiential point of view. As a relevant finding, the importance of the square in the construction and strengthening of citizenship under social and anthropological precepts that promote identity, rootedness, and sense of belonging is recognized. Likewise, the importance of diagnosing the quality of the physical environments of the city based on their form and function is determined.
\end{abstract}

Keywords: habitability; history; urban planning; square, sense of belonging Recibido: abril 9/2020
El presente artículo se deriva de una de las dimensiones de estudio de la tesis doctoral EI espacio público desde la perspectiva del colectivo infantil y el de los adultos mayores: Un estudio interdisciplinar entre la arquitectura y las ciencias sociales, desarrollada por la autora en la Universidad Politécnica de Cataluña. Este artículo, como producto de investigación, profundiza sobre las características físicas y vivenciales que deben tenerse en cuenta a la hora de estructurar, ordenar y planificar los espacios públicos de la ciudad; por lo tanto, tiene por objetivo analizar la plaza como elemento articulador y dinamizador del espacio público desde sus características físicas y vivenciales (forma, materialidad, función, uso, apropiación), y a través de las dimensiones: física, social e histórica, con el fin de determinar la importancia de la plaza dentro del desarrollo social y la planificación urbana.

Desde esta perspectiva, es importante recordar que la historia es una las principales bases que configuran el ordenamiento territorial, ya que a través de ella se ha logrado establecer dimensiones de estudio y aplicación que han contribuido, mediante la experiencia vivida, a la configuración del tejido urbano. Cada etapa que 
ha comprendido la historia de la arquitectura ha presentado un impacto en el marco de lo que hoy en día se conoce como urbe; tal es el caso de elementos históricos propios de la ciudad medieval, las antiguas Grecia y Roma, la Revolución Industrial y la Modernidad, entre otros, a través de los cuales se establecieron importantes reflexiones centradas en el tema de la ciudad y su espacio público (plaza), que permitieron generar escenarios de fortalecimiento en torno a la planificación territorial, la función social y el derecho a la ciudad.

En este sentido, la United Nations Centre for Human Settlement (UNCH, 1996) y el Objetivo de Desarrollo Sostenible (ODS) número 11 "Lograr que las ciudades y los asentamientos humanos sean inclusivos, seguros, resilientes y sostenibles" motivan al fortalecimiento de las ciudades, a través de la generación de políticas que promuevan el desarrollo social y económico de los territorios a partir del mejoramiento de la salud física y psicológica, el desarrollo integral de la población y la recuperación física del espacio. Esto, al tener en cuenta que para el 2050 más de la mitad de la población mundial vivirá en el ámbito urbano, lo cual establecerá un gran impacto en la experiencia vivida y el espacio vital de los seres humanos, tras la configuración de nuevos centros habitacionales urbanos $(\mathrm{UNCH}, 1996$, pp. 60-70; Organización de las Naciones Unidas, s.f.), como se muestra en la figura 1.

Desde esta perspectiva, se deben fortalecer los componentes físico y vivencial de la plaza como espacio y elemento urbano, por medio de estrategias direccionadas a la satisfacción de las necesidades de la calidad de vida, referentes a las dimensiones física, fisiológica, intelectual, social, histórica, material e inmaterial (Ayala García et al., 2020), en cumplimiento al bienestar de la población.

En este sentido, la arquitectura y la planificación urbana deben proponer nuevas miradas sobre los componentes del espacio público que aborden políticas, programas y proyectos basados en lineamientos integrales que permitan el fortalecimiento de espacios urbanos como las plazas, con el fin de mejorar la socialización, la apropiación y la interacción de la comunidad con respecto a la habitabilidad de la ciudad. Para esto, es pertinente reflexionar en torno a las características físicas y vivenciales que determinan la calidad de las plazas, así como el entendimiento del concepto del derecho a la ciudad, ya que de esta manera se aborda el desarrollo de la función sociocultural de la ciudad que, según autores como Rangel (2002), evoca la función recreacional, urbana, ecológica y de ocio en términos de embellecimiento, accesibilidad, calidad ambiental y diversidad; todos ellos, factores relevantes en la relación del ser humano con su entorno inmediato.

\section{Metodología}

La metodología se desarrolló a partir de una revisión documental o bibliográfica bajo la técnica de análisis de contenido, apoyada en la sistematización y la selección de recursos derivados de libros, tesis doctorales y de maestría, y artículos de bases de datos bibliográficas como Scopus, Mendeley, Science Direct y Dialnet, y que posteriormente fueron categorizados y analizados.

Esta revisión documental recabó información referida a la noción de espacio público (plaza) desde diferentes ramas del conocimiento, como la arquitectura, la sociología, la psicología, la antropología y la geografía humana. Lo anterior permitió establecer un marco teórico interdisciplinar que se centró en la construcción de una mirada holística sobre la importancia de la plaza en el desarrollo de las ciudades y en la arquitectura (Ayala García, 2017).

Los parámetros utilizados para la categorización de los textos se centraron en la comprensión de las características físicas y vivenciales (forma, materialidad, función, uso, apropiación) de la plaza, desde las dimensiones: física, social e histórica, bajo la implementación de categorías o temas de estudio como la ciudad, el urbanismo y la planeación urbana, y de palabras clave como habitabilidad, historia, planificación urbana, plaza y
(1) Figura 1. La plaza y el espacio público: una red de intercambio colectivo. Fuente: ilustración María Daniela Tami Cortes (2018) CC BY-NC

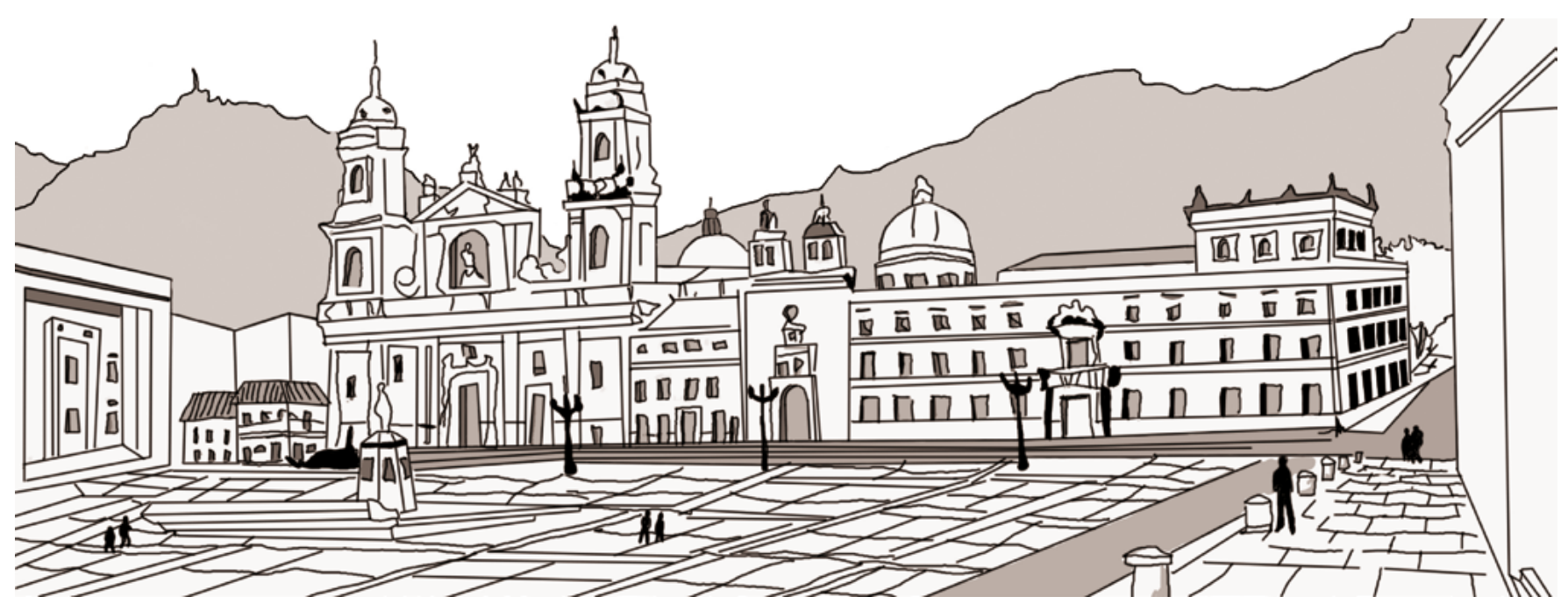


sentido de pertenencia, dentro de un contexto histórico que destacó los aspectos más relevantes de los espacios públicos y las plazas propios de la arquitectura de Egipto, Mesopotamia, Grecia, Roma, la ciudad medieval, el periodo Barroco, la Revolución Industrial y el Movimiento Moderno, bajo la mirada descriptiva de autores como Martínez de Caro y De las Rivas (1990), Llorente (2010), Campos Cortés (2011), Berroeta Torres y Vidal Moranta (2012) y Moreno y Chiarella (2001), entre otros.

Como plan de redacción, los resultados del artículo se estructuraron a partir de dos títulos. El primero, Dimensión física y composición del espacio público, en el cual se realizó una descripción de las características físicas asociadas a la calidad que deben poseer los espacios públicos, como la accesibilidad, la funcionabilidad, la seguridad y el confort, entre otros. En el segundo título, La plaza desde lo físico y lo vivencial, se reflexionó sobre la importancia de la generación de espacios urbanos de uso colectivo, enfatizando en el concepto de la plaza, descrito como un lugar espacial y temporal que congrega la experiencia física y social en la que se enmarcan la configuración material del territorio y la generación de la memoria colectiva; lo anterior, en concordancia con las dimensiones de estudio de la presente investigación.

\section{Resultados}

\section{Dimensión física y composición del espacio público}

Para Bernal Granados (2015, p. 11), el territorio urbano se comporta como un sistema de redes que se conectan entre sí por medio de relaciones estáticas, conformadas por aspectos geográficos que hacen referencia a la población, la actividad o el uso del suelo y la infraestructura, entre otros, así como por relaciones dinámicas, determinadas por el componente poblacional en el que convergen las manifestaciones materiales e inmateriales, los equipamientos y los espacios turísticos y de ocio. Para esta autora, la planeación y el ordenamiento de la urbe deben contener estrategias de intervención tendientes a la satisfacción de las necesidades básicas y el desarrollo de la ciudad con respecto al espacio público.

Desde este punto de vista, la evaluación de la calidad de los ambientes físicos de la ciudad, previstos en los componentes arquitectónicos de esta, han cobrado importancia al tener en cuenta que a través de su análisis y comprensión se puede determinar y diagnosticar la calidad y la eficiencia de aspectos como la funcionalidad, la accesibilidad, la seguridad, la iluminación, la materialidad y la señalización de los espacios públicos que la componen (Páramo \& Jiménez,1996).
Rojas Eraso (1998) menciona que esta evaluación permite comprender que los espacios públicos deben planificarse bajo propuestas integrales que contemplen estrategias que fortalezcan la accesibilidad, entendida desde el punto de vista del disfrute del espacio físico construido, la movilidad que contempla y favorece los desplazamientos, la identidad-arraigo centrada en la relación entre el ser humano y su entorno inmediato en términos de reconocimiento, uso, apropiación y transformación del espacio, la legalidad que favorece el reconocimiento y la identificación del territorio y, por último, la seguridad que hace referencia al derecho a transitar y estar libremente en el territorio. Un esquema consecuente con la teoría propuesta por Henri Lefebvre en 1969, la cual establece que los habitantes tienen el derecho a planificar, construir y crear la ciudad, y así contribuir a su transformación mediante el desarrollo de propuestas y respuestas relacionadas con la noción de la urbe basadas en las realidades sociales y espaciales de la ciudad y sus habitantes (Molano Camargo, 2016).

Con respecto a la composición física del espacio público, Gaja i Díaz (2005) plantea que su recuperación se puede lograr mediante la generación de propuestas de accesibilidad e inclusión, centradas en el fortalecimiento de aspectos como la seguridad, el confort y el atractivo, mediante estrategias como la implementación de niveles de jerarquía en los cuales prima el peatón sobre los medios de transporte no motorizado y motorizado (transporte público y privado). Por otra parte, para este autor, los espacios públicos deben contar con la presencia de hitos y mobiliario urbano de calidad que promuevan la identidad, la memoria y el arraigo, ya que de esta manera adquieren características propias, dentro de las cuales se presentan el reconocimiento, la identificación y la legibilidad, y que, sumadas a la accesibilidad y la conectividad, pueden llegar a establecer los espacios públicos como un sistema de redes o una malla estructurada que puede fortalecer características como la estancia (permanencia y apropiación), el encuentro (frecuencia y el uso) y la accesibilidad.

Sumado a lo anterior, se resalta la postura del Ministerio de Ambiente, Vivienda y Desarrollo Territorial (2005), que determina la composición del espacio público a través de tres tipos de elementos. Los primeros corresponden a los elementos naturales, debido a su importancia ambiental y su necesidad de mantenimiento y protección, como las áreas de conservación y protección del sistema orográfico y las del sistema hídrico; también, las áreas de interés paisajístico, ambiental o recreativo. Los segundos elementos hacen referencia a los componentes artificiales o construidos, dentro de los cuales establece el Ministerio los subelementos de circulación peatonal, de circulación vehicular, de articulación urbana, de encuentro $y$, finalmente, de conservación cultu- 


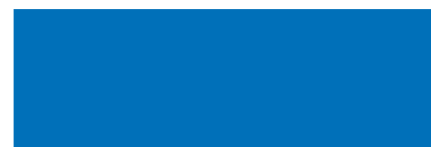

Elementos naturales
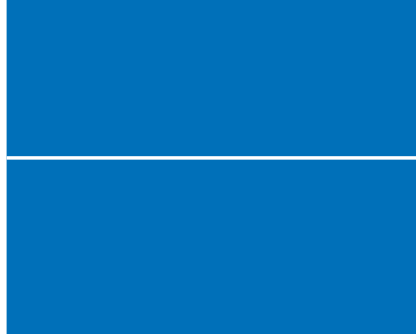

Elementos artificiales o construidos
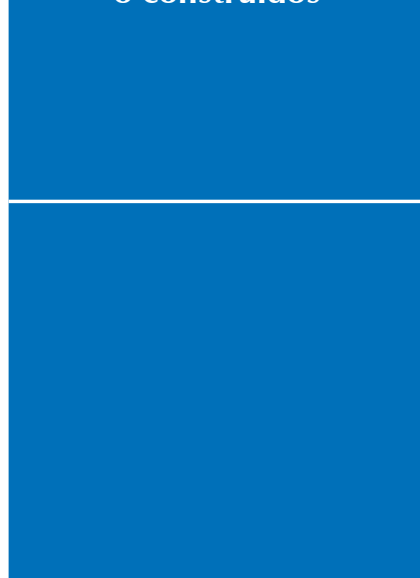

Elementos

complementarios
Área para la preservación y conservación del sistema orográfico

Área para la preservación y conservación del sistema hídrico ....................................... Áreas de interés paisajístico, recreativo y ambiental

Para circulación peatona

Para circulación vehicular

Para encuentro y articulación urbana

Conservación cultural y arquitectónica

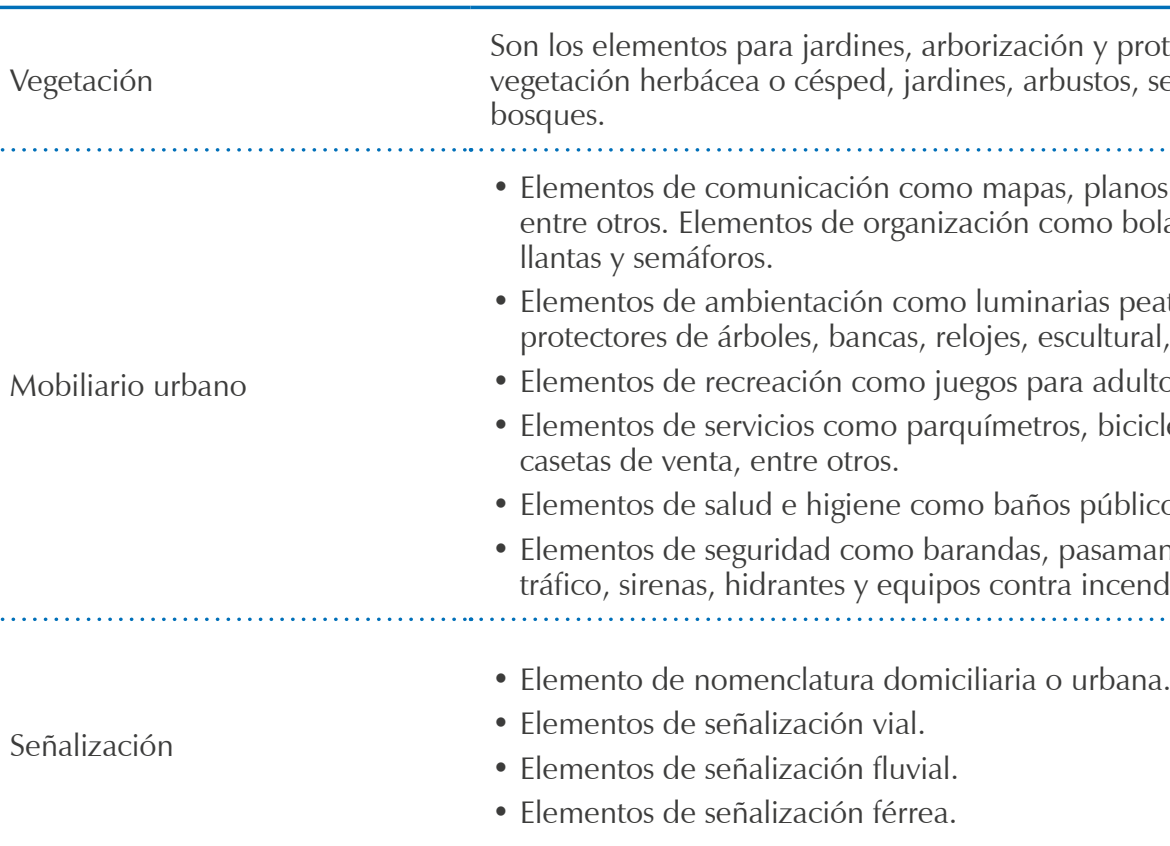
naturales y los santuarios de fauna y flora. exclusivamente al tránsito de peatones. zonas viales y pasos a desnivel. parques. que constituyen parte del patrimonio de la ciudad.
Componentes de la geografía física que por su relevancia ambiental deben ser protegidos, entre los que se encuentran cerros, montañas y colinas.

Recursos hídricos que deben ser protegidos por su relevancia ambiental como mares, playas, ciénagas, ríos, represas, canales de desagüe, etcétera.

En esta categoría se encuentran, entre otros, los parques naturales, las reservas

Estas áreas, como los andenes, las alamedas y las vías peatonales, son destinadas

Son las áreas destinadas para la circulación de vehículos como las calzadas,

Son los espacios destinados al encuentro y convivencia de los ciudadanos. Dentro de esta categoría se encuentran, por ejemplo, las plazas, plazoletas y

En esta categoría se encuentran los bienes de interés cultural y arquitectónico,

protección de paisajes como vegetación herbácea o césped, jardines, arbustos, setos o matorrales, árboles o

Elementos de comunicación como mapas, planos informadores, teléfonos, entre otros. Elementos de organización como bolardos, paraderos, topes

- Elementos de servicios como parquímetros, bicicleteros, surtidores de agua y

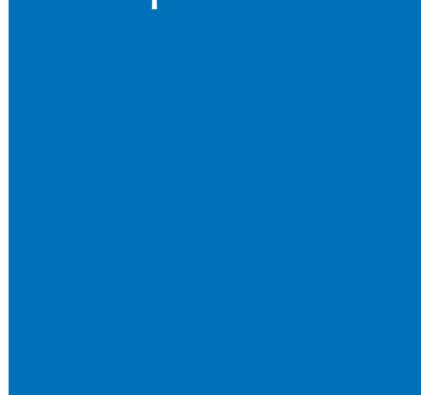

ral y arquitectónica. Los terceros elementos son los relacionados con los elementos complementarios, dentro de los cuales se estipulan la vegetación, la señalización y el mobiliario urbano, según se muestra en la tabla 1.

Desde esta perspectiva, los espacios públicos deben ser entendidos y analizados como unos de los elementos más representativos de la ciudad, al ser espacios habitados y una fuente de socialización que fortalece el tejido social, el arraigo y la identidad del territorio. Para autores como Whyte (1980), el análisis del espacio público debe abordar las esferas que encierran la comprensión, el disfrute y la interacción espacial del ser humano dentro de los entornos que hacen parte de su cotidianidad.

Para este autor, los espacios públicos son de alta complejidad, para la interacción y para el cambio constante, por lo cual se debe estudiar su grado de efectividad con respecto al uso, así como a la satisfacción de quienes cotidianamente los apropian. Para lograr tal fin, este autor establece cualidades indispensables para el éxito de los espacios públicos, donde define como atribu- tos principales cuatro categorías: la accesibilidad y la conexión, la sociabilidad, la imagen y el confort, y el uso o la actividad.

En este orden de ideas, la dimensión física y la composición del espacio público deben contemplar, además de la mirada arquitectónica, los estudios y las reflexiones derivados de las ciencias sociales, ya que solo de esta manera se puede abordar holísticamente la complejidad de este espacio que dentro de la ciudad se presenta, se vive y se experimenta de una manera no solo física o material, sino también, vivencial o intangible. En este sentido, tienen importancia los aportes derivados de autores como Rainero et al. (2006) y Muxi et al. (2011), para quienes la materialidad física-construida propia del espacio público cobra sentido y se encuentra directamente relacionada con los principios de ver y ser visto, de señalización, de concurrencia de personas, de accesibilidad, de mantenimiento y de la participación comunitaria, propios de la planificación urbana para la seguridad de la ciudad.

Además de lo anterior, en 1986 el Concilio de Europa definió los espacios públicos de la ciudad
A Tabla 1. Componentes del espacio público.

Fuente: Ministerio Ambiente, Vivienda y Desarrollo Territorial (2005, pp. 13-16). 


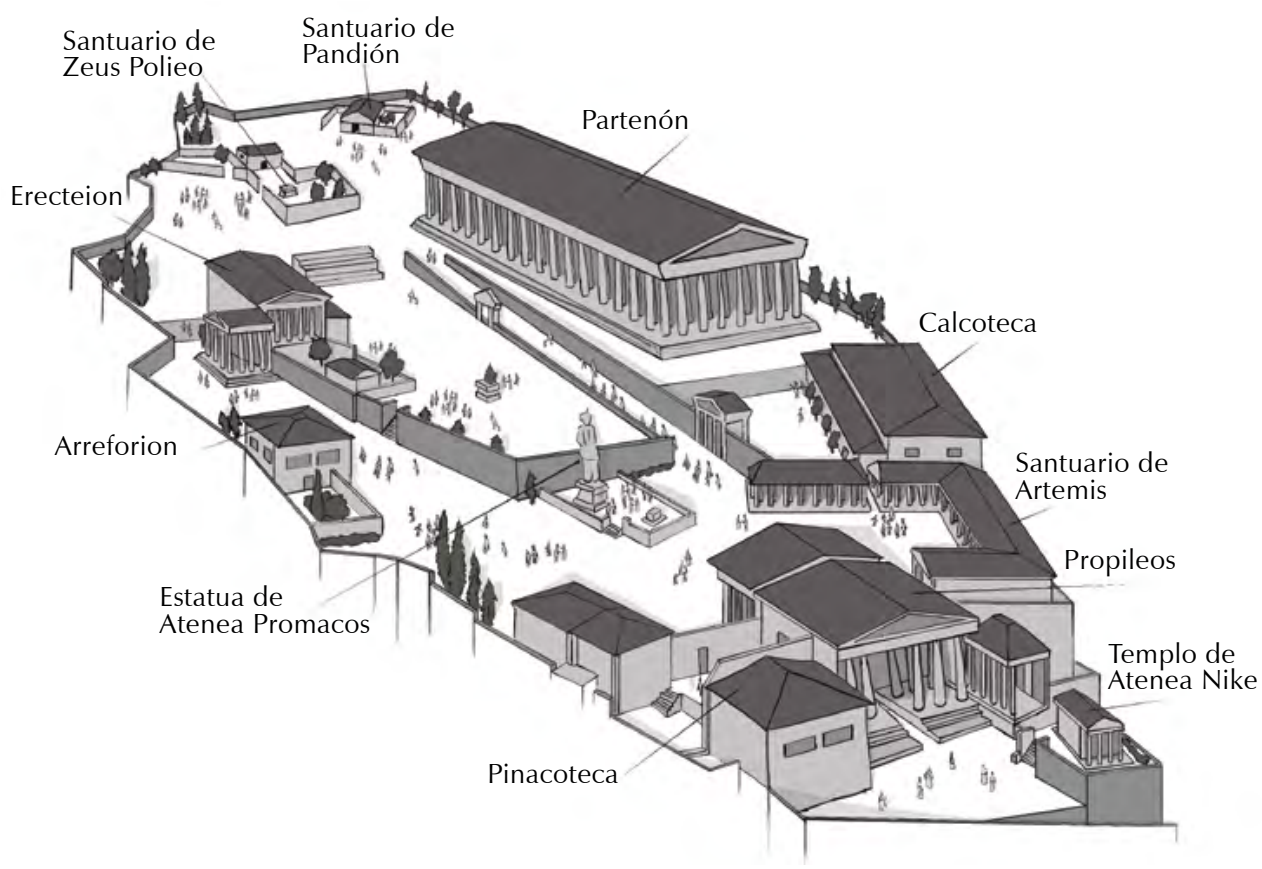

(A) Figura 2. La acrópolis de Atenas.

Fuente: ilustración María Daniela Tami Cortes (2021). CC BY-NC poral y social centrada en la vida cotidiana que establece una narrativa de experiencias donde convergen las vivencias que configuran el sentido del lugar (sense of place) (Ferretti et al., 2018; Ortiz et al., 2004).

En este orden de ideas, un espacio físico construido de uso colectivo como la plaza adquiere un significado importante con respecto a su carácter socializador y su incidencia dentro del territorio, ya que, en palabras de Habermas (1981), permite determinar aspectos importantes para la configuración de la ciudad desde lo público, como el patrimonio material y la memoria colectiva. Estos hechos significantes revelan el espacio vital y la experiencia cotidiana del ser humano dentro de los espacios que hacen parte de su cotidianidad sustentando la función social de la ciudad (Bernal Granados, 2015) que fortalece la identidad y la ciudadanía, mediante el reconocimiento y la apropiación de lo físico (territorio) y la promulgación de la memoria tanto individual como colectiva (De Certeau, 2000).

Para autores como Campos Cortés (2011), el concepto de plaza representa el reconocimiento de las masas, en términos de diversidad, multiculturalidad y pluralidad social, cultural y política. Estos componentes se encuentran arraigados en la experiencia cotidiana individual o colectiva que fortalecen la noción de ciudad, bajo una construcción de lo público que da sentido al imaginario urbano social de la población; estructura el territorio, organiza y articula la malla urbana (Bazant, 2010).

En el ámbito histórico se resalta que el concepto de plaza, desde la perspectiva de lugar de encuentro o espacio de socialización según Martínez de Caro y de las Rivas (1990), se remonta a espacios geográficos como Çatalhöyük (en la antigua Anatolia), Egipto y Mesopotamia, lugares donde los espacios públicos eran destinados al intercambio de objetos y productos, además del desarrollo de ceremonias en honor a los dioses. Campos Cortés (2011) reflexiona en torno a las plazas grecorromanas enfatizando en que estos espacios se destinaban al desarrollo de actividades económicas, pero que, al mismo tiempo, eran los encargados de albergar las funciones derivadas de los componentes políticos y religiosos. En relación con la composición física de la misma, esta autora menciona que:

La plaza griega gira en torno a un edificio para el culto de héroes y dioses, y un edificio para la asamblea, que contenía las oficinas de los magistrados, los almacenes y el archivo, complementado con un espacio abierto y multifuncional, dedicado a satisfacer la función económica. Para los romanos, la plaza pública se representaba por el foro, que estaba cerrado por pórticos, y contenía los locales comerciales y la sede del senado, razón por la cual, posteriormente, se desarrolló una separación entre el foro civil y el foro del mercado. (Ayala García, 2018, p. 58) 


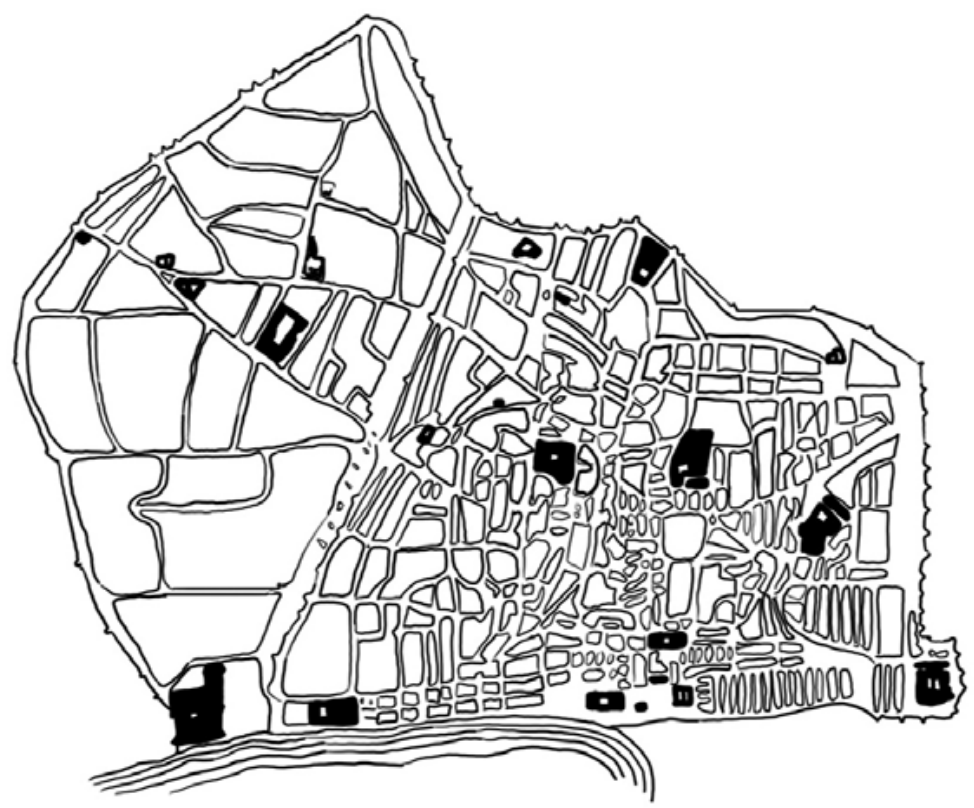

Berroeta Torres y Vidal Moranta (2012) aseguran que el espacio público griego no se comportó como el espacio para la expresión sobre el interés común, abierto y manifiesto, y lo definen, en cambio, como un espacio poco incluyente, de carácter elitista y homogéneo, en el cual el desarrollo de la función social del espacio público, el disfrute y la convivencia se vieron restringidos, según se muestra en la figura 2.

En el caso de la ciudad medieval, la construcción de lo público rompió el esquema ceremonial antes mencionado, y se centró en la experiencia vital que trae consigo el aprendizaje cotidiano. Por tal razón, sus incipientes trazas urbanas evidenciaron el desarrollo de las artes y los oficios, y sus espacios se convirtieron en los primeros escenarios urbanos de uso mixto, bordeados por circulaciones donde se dio lugar a las festividades populares y el encuentro ciudadano (López de Lucio, 1993).

Como se puede apreciar en la figura 3, a diferencia de los espacios grecorromanos, la plaza pública medieval interactuó directamente con las unidades habitacionales encargadas de marcar los límites de la trama general, compuesta por viviendas, plazas y calles que se conjugan por medio de llenos y vacíos, con el fin de dar cumplimiento a las funciones de la ciudad. Los espacios públicos de las ciudades medievales se caracterizaron por ser abiertos, accesibles y de uso común (Berroeta Torres \& Vidal Moranta, 2012).

Esta configuración aplicó a las características de los espacios públicos del Renacimiento, los cuales, de acuerdo con su configuración sinuosa, conformaron en muchas oportunidades líneas de latigazo o serpentina, donde, al igual que en las ciudades medievales, se mezclaron los usos residenciales y comerciales; por tal razón, dentro de este periodo el espacio urbano por excelencia para disfrutar, compartir y socializar fue la plaza.

La plaza pública era el punto de convergencia de

lo extraoficial y gozaba de un cierto derecho a

la 'extraoficialidad' dentro del orden y la ideo-

logía oficiales; en este sitio, el pueblo llevaba la
Figura 3. Barcelona a finales de la Edad Media. Fuente: ilustración María Daniela Tami Cortes, a partir del Archivo Histórico de Barcelona (2018). CC BY-N

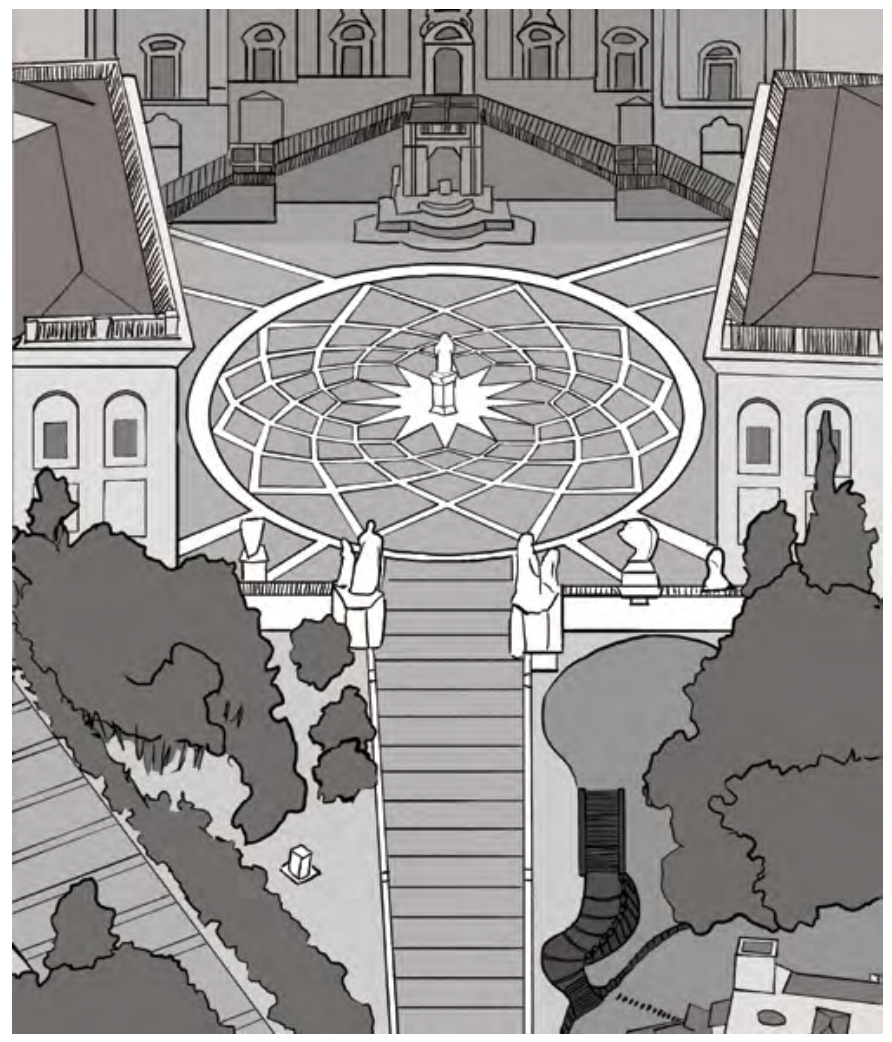

voz cantante [...] La cultura popular extraoficial tenía un territorio propio en la Edad Media y en el Renacimiento: la plaza pública [...] Reinaba allí una forma especial dentro de la comunicación humana: el trato libre y familiar. En los palacios, templos, instituciones y casas privadas, reinaba en cambio un principio de comunicación jerárquica, la etiqueta y las reglas de urbanidad. En la plaza pública se escuchaban los dichos del lenguaje familiar, que Ilegaban casi a crear una lengua propia, imposible de emplear en otra parte, y claramente diferenciado del lenguaje de la corte, de los tribunales, de las instituciones públicas, de la literatura oficial, y de la lengua hablada por las clases dominantes. (Bajtín, 1994, en Sato, 2012, p. 18)

El trazado urbano de la ciudad del Renacimiento optó por la generación del concepto de una ciudad ideal, que albergó de manera organizada hitos representativos que marcaron el imaginario urbano social de los habitantes; la plaza principal se convirtió en el elemento urbano de máxima representación y jerarquía, asociado a una red de espacios públicos organizados (por medio de calles paralelas conectadas entre sí) y planificados que terminaron de establecerse y configurarse dentro de la ciudad del periodo Barroco, tal cual se ve en la figura 4.

El concepto de la ciudad ideal, según autores como Moreno y Chiarella (2001), trajo como consecuencia una afectación directa para los espacios públicos de la ciudad barroca, bajo el marcado interés de afectar enfáticamente las plazas de la ciudad, y así reforzar el espíritu lúdico,
A Figura 4. Piazza di Campidoglio, Roma. Remodelación Michelangelo Buonarroti.

Fuente: ilustración de María Daniela Tami Cortes (2021). CC BY-NC 

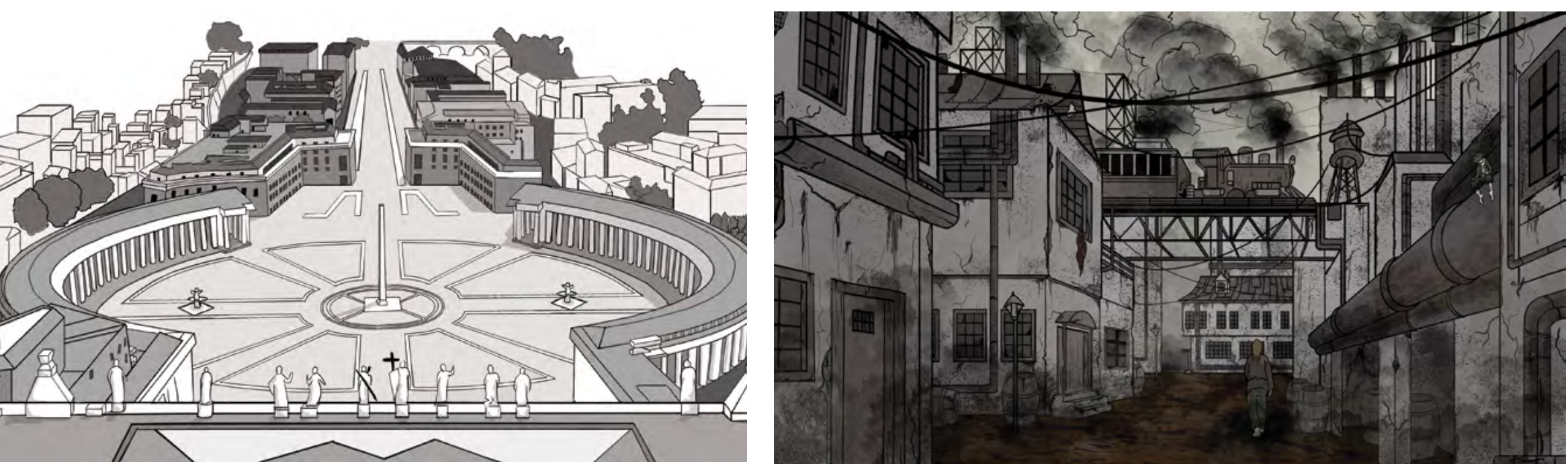

(4) (1) Figura 5. Piazza San Petro socializador, el derecho a ser, estar y disfrutar de y Via della Conciliazione, por los habitantes con respecto a la noción del espaGian Lorenzo Bernini.

Fuente: ilustración de María Daniela Tami Cortes (2021). CC BY-NC

(A) (A) Figura 6. La ciudad industrial.

Fuente: ilustración de María Daniela Tami Cortes (2021). CC BY-NC cio público; esta vez, mediante fiestas y celebraciones. Por lo tanto, el legado de la ciudad barroca correspondió a un modelo de planificación urbana centrado en la monumentalidad y la jerarquía, en el cual sus calles, sus plazas y su arquitectura configuraron un sistema unitario que se alimentó de las artes visuales (Castex, 1994). En este sentido, el espacio público, entendido como la calle, la plaza y la plaza real, se convirtió en el telón de fondo del urbanismo por medio del cual la ciudad fue comprendida como el escenario (público y privado) de la vida urbana, como se muestra en la figura 5 .

\begin{abstract}
La ciudad barroca aspiró a ser la expresión de una estructura político-social absolutista, donde la subordinación de las partes a una idea general unificadora resultaba esencial. Dentro de este planteo, la ciudad planificada y diseñada de una sola vez era la ideal [...] apeló al trazado de calles rectas, a la construcción de plazas regulares y a la creación de nuevos barrios en retícula. La organización urbana estuvo definida por centros -edificios o plazas- intercomunicados por calles rectas y regulares, siendo uno de los centros generalmente dominante. Como afirma Norberg-Schulz el carácter dinámico y abierto de la ciudad barroca se expresaba también en su estructura interior. Las calles anchas y rectas permitían intenso tránsito de personas y vehículos, de acuerdo con las nuevas necesidades de participación haciendo patente el deseo de sistematización [...] así como el ámbito de las fiestas cívicas. (Moreno \& Chiarella, 2001, pp. 1076-1080)
\end{abstract}

La Revolución Industrial configuró aspectos negativos, relacionados con la planeación urbana, la salubridad, la calidad de vida y los espacios públicos, como en el caso de Inglaterra. Marta Llorente Díaz (2010) asegura que desde finales del siglo XVIII el paso de la industrialización afectó considerablemente la relación entre la arquitectura y el territorio, en razón de que el acelerado proceso de crecimiento poblacional generó la incapacidad para brindar los elementos propios de la calidad de vida urbana. Quizá, uno de los ejemplos más claros obedece al cambio de flujo poblacional de Barcelona y Londres, ya que entre 1800 y 1910 Barcelona pasó de 115000 habitantes a 472 000, y Londres pasó de 1117000 a 7256000 habitantes. Según lo anterior, la población de Barcelona se multiplicó por cuatro, y la de Londres, ya diez veces mayor, se multiplicó entre seis y siete veces (Llorente Díaz, 2010, p. 227).

Para Llorente Díaz (2010), la industrialización en sus primeras etapas trajo consigo huellas significativas en el tejido urbano, caracterizadas por la degradación del medio habitado

\begin{abstract}
[...] en el cual se podía apreciar con facilidad el manto de gases producidos por las chimeneas fabriles, el detritus urbano, el cambio en la lectura del paisaje urbano como respuesta a la aparición acelerada y desorganizada de los depósitos de gas, los almacenes, las fábricas y las chimeneas, la multiplicación de los vehículos, la transformación de la noche en espacio lúdico y productivo en virtud de las nuevas luces de gas, la fragmentación de los espacios que crearon microestructuras habitadas, como contra punto siniestro de las estructuras en que se iban transformando las ciudades. (p. 226)
\end{abstract}

Luego del crecimiento acelerado de la población y la densificación del territorio bajo las características de la Revolución Industrial, se produjo un cambio de pensamiento que condujo al redireccionamiento no solo de la ciudad, sino de la configuración y la generación de los espacios que esta alberga, como se ilustra en la figura 6 .

Para Berroeta Torres y Vidal Moranta (2012), la Declaración de los Derechos del Hombre y del Ciudadano, producida a finales del siglo XVIII, configuró una nueva relación entre lo público y lo privado ejerciendo una incidencia en la idea sobre el espacio público, que ahora se centró en la generación de espacios de uso colectivo y fomentó la interacción de los habitantes con el territorio mediante preceptos de igualdad. Se apostó por la planeación de espacios públicos centrados en el discurso moderno, que incitó la puesta en marcha de normas de convivencia y planeación establecidas a partir del cumplimiento de componentes como la accesibilidad, lo público y lo común. 
Para estos autores, los espacios públicos retomaron la noción asociada a su espacialidad y su materialidad física, en la cual predominó la utilización de plazas ajardinadas en espacios geográficos, como en la París del siglo XIX, donde, bajo el direccionamiento del Barón de Haussmann y Napoleón III, se dio inicio a transformaciones urbanas que cambiaron nuevamente la lectura de la ciudad respecto a la funcionalidad y el disfrute, con el propósito de establecer un nuevo modelo para el contexto europeo. Esta idea de cambio se contempló en la composición física del espacio público a través de la eliminación de "las callejuelas sinuosas", que dieron paso a calles anchas y rectas, al igual que a la creación de infraestructuras y servicios como parques, alcantarillados, transporte público, mercados y escuelas, entre otros, según se ve en la figura 7 . El espacio público, a través del bulevar y el parque, se destacó por su belleza y su funcionalidad, ya que sus diseños articularon el espacio a través de elementos verdes, zonas duras y mobiliario urbano, que tuvieron como propósito brindar confort al usuario estableciendo al peatón como el nuevo protagonista de la ciudad (Berman, 1991).

El movimiento moderno propuso la conceptualización de una ciudad diferente, centrada en la racionalidad, la funcionabilidad, la jerarquía espacial y el rompimiento con la memoria propia de la ciudad histórica. Se destacan las propuestas de Le Corbusier, como la Ville Contemporaine (1922) y Ville Radieuse (1930), que establecieron diversos espacios públicos donde primaron el encuentro y la socialización, aspectos que fueron en contravía de las características de la ciudad industrial del siglo XIX. Estas propuestas utilizaron patrones de diseño que vincularon la naturaleza al espacio público (Alonso García, 2016); sin embargo, la división y la especialización de sus espacios llevaron a que nuevamente se alterara la forma como los habitantes utilizaban, apropiaban y transformaban los espacios públicos, como se ilustra en la figura 8.
Gamboa Samper (2003) menciona que en el Modernismo la arquitectura se desvinculó de la calle, y configuró el edificio como un elemento jerárquico bordeado por un espacio libre y vacío que se alejó de la noción de socialización e intercambio comunitario, ya que comúnmente las plazas hacían parte de espacios residenciales generalmente cerrados.

\begin{abstract}
De otra parte la ciudad moderna no se recorre, como se hacía con los bulevares o con las calles [...] sino que se atraviesa; no se recorre porque cada vez son más reducidos los lugares (significación y orden formal) que puedan tener un sentido social de relación e intercambio, lugares que van quedando aislados dentro de la gran ciudad, dejando de conformar una red continua de espacios públicos para convertirse en un sistema de puntos, de enclaves limitados que deben ser alcanzados atravesando áreas «vacías» (mono funcionales, casi siempre). Vacías no porque no estén construidas, sino precisamente porque no son lugares urbanos que puedan soportar una vida pública. (Gamboa Samper, 2003, p. 18)
\end{abstract}

\section{Discusión}

El análisis y la planeación urbana son mecanismos esenciales que contribuyen al entendimiento de la dimensión física del territorio, que permiten comprender la importancia y la incidencia del entorno físico-vivencial para el ser humano y su hábitat (Norberg-Shulz, 2000; Tricart \& Killian, 1982). Desde este punto de vista, a partir del análisis histórico desde las características físicas y vivenciales realizado para esta investigación, queda en evidencia que las plazas han sido lugares que promueven el encuentro, la socialización, la integración cultural, la identificación
(7) Figura 7. La cotidianidad en París (siglo XIX).

Fuente: ilustración de María Daniela Tami Cortes (2021) a partir de una fotografía de Roger-Viollet/Aurimages para Historia-National Geographic. CC BY-NC

(1) (1) Figura 8. Ville Radieuse (Le Corbusier)

Fuente: ilustración de María Daniela Tami Cortes (2021). CC BY-NC
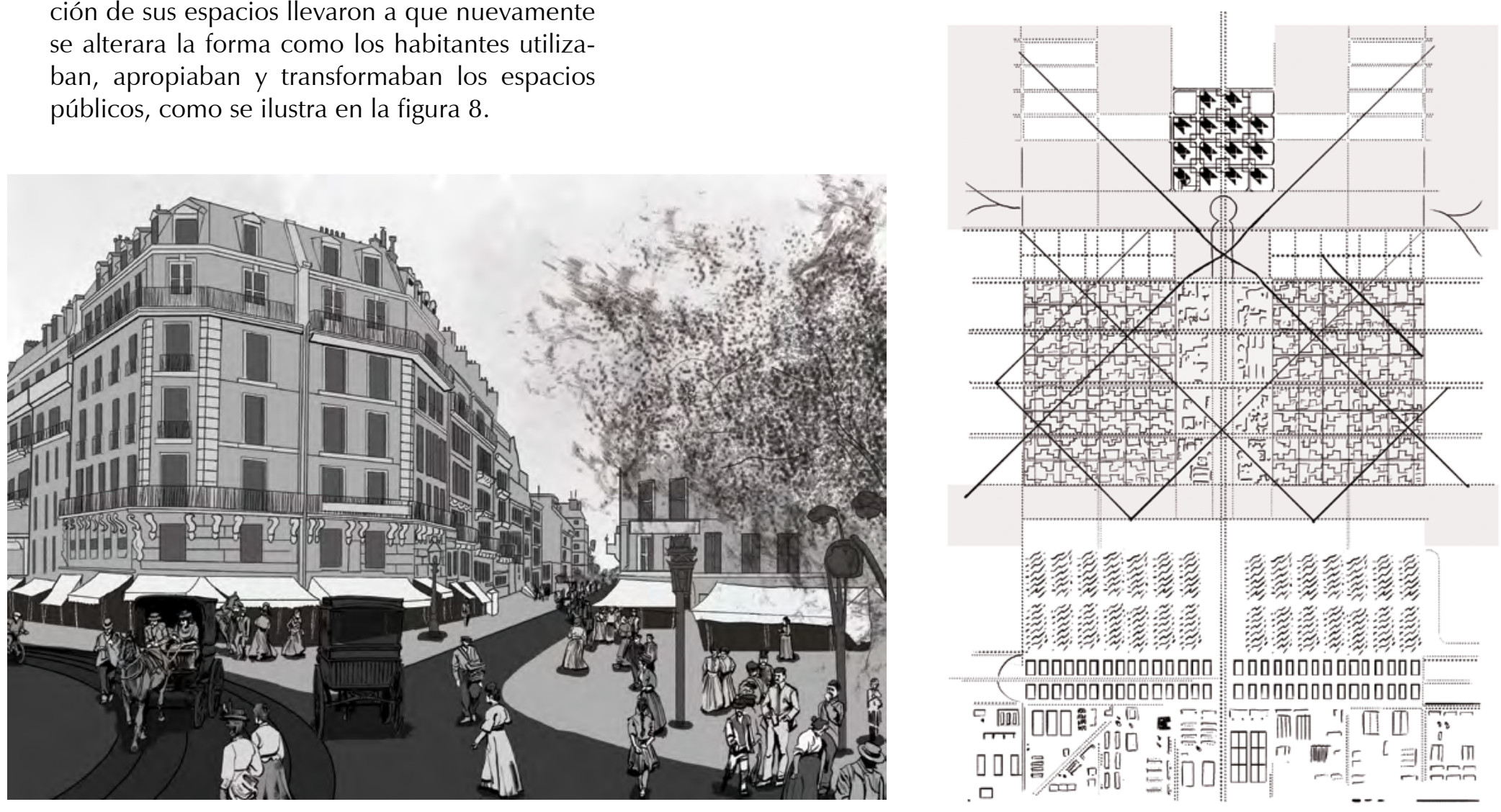

Vol. 
(1) Figura 9. Tipologías morfológicas de plazas. Fuente: ilustración María Daniela Tami (2018) a partir de Arquitectura urbana, de Martínez Caro y De las Rivas (1990). CC BY-N elementos de teoría y diseño,

simbólica, el arraigo y el desarrollo sociocultural; y además, que su dimensión física (morfología, función, tipología y materialidad) influye en el desarrollo sociocultural de la población.

De esta manera, con el fin de fortalecer el sentido socializador y el uso de las plazas, es necesario integrar, desde el proceso de diseño, recuperación o intervención del espacio público, una perspectiva que consolide sus dimensiones física, social e histórica, a través de la cual se pueda obtener una respuesta dirigida al fomento del uso y la apropiación del espacio generando una transformación y un impacto positivo del entorno inmediato, así como del bienestar de la población que lo utiliza, para así dar cumplimiento a lo establecido por el Ministerio de Ambiente, Vivienda y Desarrollo Territorial (2005) y el objetivo número 11 de la Organización de Naciones Unidas (s.f.).

Con respecto a la morfología de las plazas, Gordon (1954) y Rob Krier (1981), en Martínez de Caro y De las Rivas (1990), establecen que durante el Renacimiento su configuración formal obedeció a la eliminación de la masa construida (edificios) bajo esferas de proporcionalidad espacial entre llenos y vacíos; sin embargo, a partir de los siglos XVII y XVIII la forma urbana permitió la aparición de nuevas tipologías morfológicas, tales como las plazas cuadradas, caracterizadas por ser un elemento central ajardinado que otorga conectividad con las zonas residenciales que la rodean; las plazas rectangulares, que aprovechan el espacio útil y se abren camino entre edi-
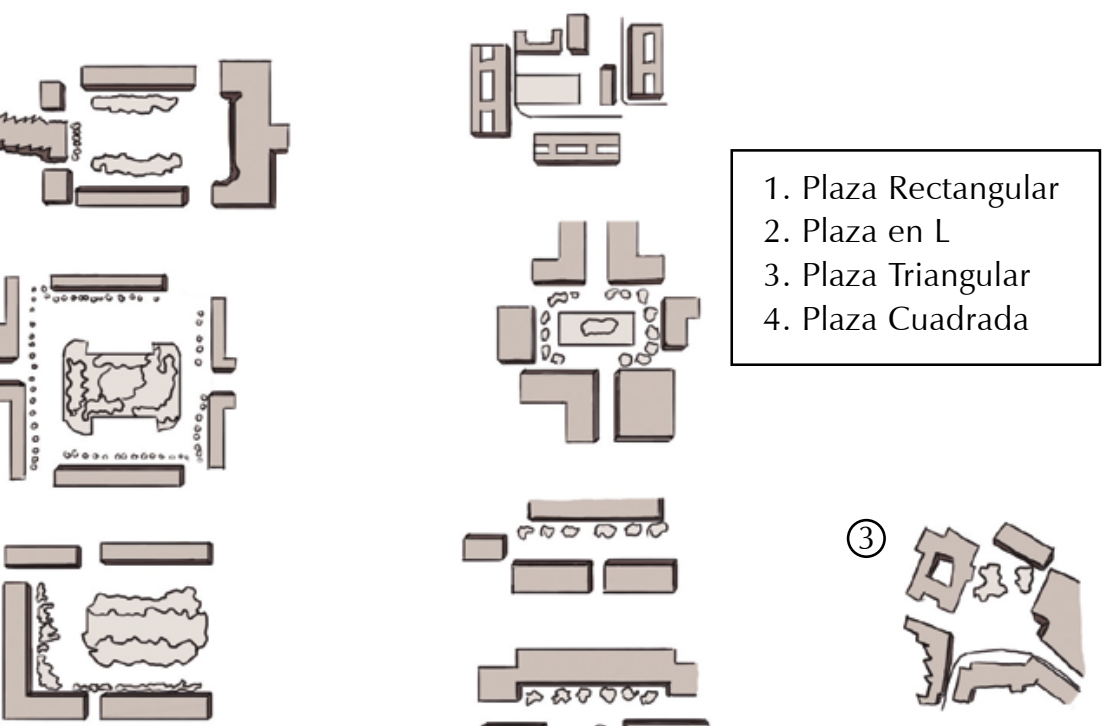

(1)

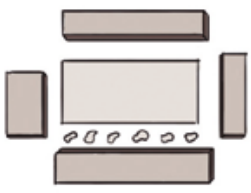

(2)
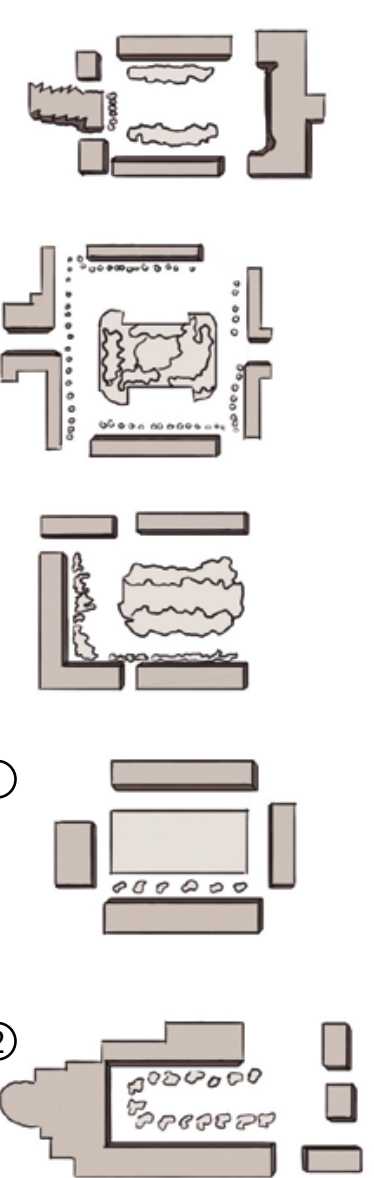

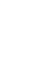
. 
de uso cotidiano. Por lo tanto, la plaza, como espacio urbano de la ciudad, es la encargada de reorganizar, articular y dar sentido a la malla urbana (Perahia, 2007) desde las dimensiones física, social e histórica.

De esta manera, la plaza adquiere importancia como elemento dinamizador y articulador del espacio público y generador de actividades a partir de sus características físicas y vivenciales, las cuales influyen en los procesos de planificación y desarrollo social de las ciudades, y que, en palabras de Carvalho (2007),

\section{[...] centran el uso y la apropiación constante de los espacios y la infraestructura destinada para el disfrute o el ocio, establecen una relación entre el sujeto (actor) y la experiencia vivida [...]. (p. 98)}

Para autores como Perico-Agudelo (2009), la relación entre la plaza y el ser humano se encuentra directamente asociada a la percepción del ambiente urbano, por medio de su relación con las características físicas (materiales, texturas, vegetación, temperatura, color, humedad, confort térmico, luminosidad, aspectos visuales, sonoros y olfativos) y las características vivenciales (experimentación, experiencia vivida subjetiva y objetiva, uso, apropiación y transformación espacial con respecto al derecho a la ciudad) propias de este espacio urbano.

\section{Conclusiones}

La plaza como elemento urbano configura un aspecto importante dentro de la planificación del territorio, al considerársela un espacio articulador que contribuye al mejoramiento del territorio y al bienestar de la población, en pro del derecho a la ciudad. En este sentido, la plaza, a través de sus características físicas y vivenciales, determina el cumplimiento del ordenamiento, la articulación de la malla urbana y la interacción del ser humano con el entorno físico construido, y genera así narrativas de experiencias que alimentan el arraigo, la territorialidad, la identidad, la identificación, la legibilidad, la accesibilidad, la memoria, la conectividad y el mejoramiento del paisaje urbano.

El desarrollo de esta investigación es un aporte al conocimiento, al considerar el estudio de la plaza un insumo para la planificación urbana y el desarrollo social del territorio, a partir sus características físicas y vivenciales (forma, materialidad, función, uso, apropiación) y a través de las dimensiones física, social e histórica. La metodología aplicada a esta investigación permitió realizar una reconstrucción histórica con respecto a las principales características de la plaza en diferentes épocas de la historia de la humanidad. Esto favoreció el reconocimiento de sus particularidades y de su importancia con respecto al desarrollo del territorio, en cada uno de los casos.

En este sentido, desde la dimensión histórica se concluyó que cada una de las épocas aborda- das le otorgó atributos diferentes a la plaza, que impactaron tanto el aspecto morfológico como el vivencial de la ciudad. Desde esta perspectiva, se determinó que la planificación urbana a partir de la idealización de la ciudad favoreció el fortalecimiento de las características físicas y vivenciales de la plaza como un elemento urbano que ocupó un lugar significativo en los periodos del Renacimiento y el Barroco, en los cuales adquirió su máxima representación y su máxima jerarquía fortaleciendo, a través de sus características físicas, la organización de la malla urbana, y a partir de sus características vivenciales, el carácter lúdico y socializador del espacio público y, por lo tanto, el derecho a la ciudad.

Como respuesta al estudio de las características físicas, se concluyó que el reconocimiento de aspectos como la funcionalidad, la movilidad, la accesibilidad, la seguridad, la iluminación, la materialidad y la señalización de las plazas permite diagnosticar la calidad de los ambientes físicos del componente del espacio público de la ciudad; así mismo, que con respecto a la forma y función, los diseños donde se proyecten plazas deben contemplar un análisis de usos del suelo, a través del cual se garantice el nivel de interacción (diversificación de actividades, flujos, temporalidades y frecuencias de uso), que trae como consecuencia el fortalecimiento del perfil económico y sociocultural de la ciudad.

Con respecto a las características vivenciales, se reconoció la importancia de la plaza en la construcción y el fortalecimiento de la ciudadanía, bajo preceptos sociales que la determinan como el medio propicio para generar y fortalecer la identidad, el arraigo, el sentido de pertenencia y de lugar; como un topos antropológico. En este sentido, se concluye que la plaza es un escenario potencializador de la experiencia humana vital, coherente con el papel socializador del espacio público, y donde el ser humano tiene la posibilidad de generar un reconocimiento espacial y vivencial que promueve y fortalece los niveles de apropiación y cohesión de la sociedad, en materia tanto morfológica como funcional.

Lo anterior deja en evidencia la pertinencia de desarrollar proyectos coherentes con los contextos geográfico y sociohistórico, y con las necesidades del ser humano en cada territorio. La arquitectura y la planificación urbanas están llamadas a proponer espacios con características físicas y vivenciales que, en términos de materialidad, confort, accesibilidad, uso, disfrute y apropiación, permitan dar cumplimiento al derecho a la ciudad. Se deben desarrollar estrategias de análisis y evaluación de las plazas con el fin de fortalecer y promover intervenciones que respondan a las dimensiones física, social e histórica, a través de las cuales se mejoren la percepción y la interacción con el ambiente urbano, se incentive la apropiación de la comunidad y se promuevan el arraigo, la identidad y la identificación con respecto al territorio. 


\section{Referencias}

Alonso García, E. (2016). El espacio público en Le Corbusier. Evolución de su pensamiento y de sus estrategias formales. En Le Corbusier 50 años después (pp. 74-98). Editorial Universitat Politècnica de València. https://doi.org/10.4995/LC2015.2015.1012

Ayala García, E. T. (2017). La ciudad como espacio habitado y fuente de socialización. Revista Ánfora, 24(42), 189-216.

https://doi.org/10.30854/anf.v24. n42.2017.170

Ayala García, E. T. (2018). El espacio público desde la perspectiva del colectivo infantil y el de los adultos mayores: un estudio interdisciplinar entre la arquitectura y las ciencias sociales [Tesis doctoral, Universidad Politécnica de Cataluña].

h t t p s : / / u p com m on s.upc.edu / handle/2117/125314

Ayala García, E. T., Ayala Santos, R., \& Hernández Suárez, C. A. (2020). El papel de la arquitectura ante los problemas de calidad de vida de la población víctima del conflicto armado colombiano. Revista Encuentros, 18(01).

https://doi.org/10.15665/encuent. v18i01.2156

Bajtín, M. (1994). La cultura popular en la Edad Media y en el Renacimiento. El contexto de François Rabelais. Alianza Estudio.

Bazant, J. (2010). Espacios urbanos, historia, teoria y diseño. Limusa.

Berman, M. (1991). Todo lo sólido se desvanece en el aire. La experiencia de la modernidad. Siglo XXI editores.

Bernal Granados, M. A. (2015). Análisis y diagnóstico urbano-regional. Metodología para la caracterización territorial. Universidad Piloto de Colombia.

Berroeta Torres, H. \& Vidal Moranta, T. (2012). La noción de espacio público y la configuración de la ciudad: fundamentos para los relatos de pérdida, civilidad y disputa, Polis http://journals.openedition.org/polis/3612

Campos Cortes, G. I. (2011). El origen de la plaza pública en México: Usos y funciones sociales. Argumentos, 24(66).

Carvalho Marcellino, N. (2007). Lazer e cultura. Alinea.

Castex, J. (1994). Renacimiento, Barroco y Clasicismo. Ediciones Akal S.A.

De Certeau, M. (2000). La invención de lo cotidiano I. Artes de hacer. Universidad Iberoamericana.

Dos Anjos, F. A., Tavares, L. J., \& Baptista López, V. (2009). La organización del espacio público y privado en área central del sistema turístico. Estudios y perspectiva en turismo, 18(5).

h t t p s : / / w w w. red a I y c.org / pdf/1807/180713902005.pdf

Driver, B. (2015). Social benefits of urban forests and related green spaces. En R. Miller, \& R Euer, Urban forestry: Planning and managing urban green spaces (pp. 98-113). Waveland Press.

Ferretti, M., Navarrete-Escobedo, D., \& Álvarez-Pedrosian, E. (2018). Las disputas por el sentido y sus lógicas de emplazamiento en la escena urbana neoliberal. Revista de Arquitectura, 20(1), 14-23. h t t p s://do i . org/10.14718/ RevArq.2018.20.1.1535

Gaja i Díaz, F. (2005). Revolución informacional, crisis ecologica y urbanismo. Universidad Politécnica de Valencia.
Gamboa Samper, P. (2003). El sentido urbano del espacio público. Revista Bitácora Urbano Territorial, 1(7), 13-18.

https://revistas.unal.edu.co/index.php/ bitacora/article/view/18775

Gordon, L. (1954). The urban scene. Faber.

Habermas, J. (1981). Historia y crítica de la opinión pública. La transformación estructural de la vida pública. Gustavo Gili.

Krier, R. (1981). El espacio urbano. Gustavo Gili.

Kuri Pineda, E. (2017). La construcción social de la memoria en el espacio: una aproximación sociológica. Península, 12(1), 9-30. https://doi.org/10.1016/j.pnsla.2017.01.001

Lefebvre, H. (1969). El derecho a la ciudad. Universidad Estatal de Pensilvania.

Leva, G. (2005). Indicadores de calidad de vida teoría y metodología. Universidad Nacional de Quilmes.

López de Lucio, R. (1993). Ciudad y urbanismo a finales del siglo XX. Universitat de Valencia.

Llorente, M. (2010). La ciudad: inscripción y huella. Escenas y paisajes de la ciudad cons truida y habitada, hacia un enfoque antropológico de la historia urbana. UPC. http://hdl.handle.net/2099.3/36659

Martínez Caro, C., \& De las Rivas, J. (1990). Arquitectura urbana: elementos de teoría y diseño. Belisco.

Ministerio de Ambiente, Vivienda y Desarrollo Territorial. (2005). Guía metodológica 5: Mecanismos de recuperación del espacio público.

http://observatorio.dadep.gov.co/documento/ guia-metodologica-5-mecanismos-derecuperacion-del-espacio-publico

Molano Camargo, F. (2016). El derecho a la ciudad: de Henri Lefebvre a los análisis sobre la ciudad capitalista contemporánea. Revista Folios, (44), 3-19.

Moreno, D., \& Chiarella, A. L. (2001). Rasgos barrocos en la génesis de los espacios públicos americanos. En Actas III Congreso Internacional del Barroco Americano: Territorio, Arte, Espacio y Sociedad (p. 83). Universi dad Pablo de Olavide.

Muxi, Z., Ciocoletto, A., \& Ortiz, S. (2011). Construyendo entornos seguros desde la perspectiva de género. En M. Freixanet, No surtis sola. Espais públics segurs amb perspectiva de gèner (pp. 145-182). Institut de Ciències Politiques i socials.

Norberg-Shulz, C. (2000). Architecture: Presence, language and place. Radom House Incorporated.

Ortiz, A., García-Ramón, M. D., \& Prats, M. (2004). Women's use of public space and sense of place in the Raval (Barcelona). GeoJournal, 61, 219-227. https://doi.org/10.1007/s10708-004-3539-0

Organización de las Naciones Unidas (s.f.) Objetivo 11. Las ciudades desempeñarán un papel importante en la consecución de los Objetivos de Desarrollo Sostenible. https://www.un.org/es/chronicle/article/ objetivo-11-las-ciudades-desempenaranun-papel-importante-en-la-consecucion-delos-objetivos-de

Páramo, P., \& Jiménez, L. (1996). Conceptualización de arquitectos y no arquitectos de barreras arquitectónicas en los espacios públicos, semi públicos y privados. Suma psicológica, 3(1), 53-74.

h t t p ://dx.doi.org/10.14349/ sumapsi1996.278

Perahia, R. (2007). IX Coloquio Internacional de Geocrítica "Los problemas del mundo actual, soluciones y alternativas desde la geografía y las ciencias sociales". Las ciudades y su espacio público. Universidade Federal do Rio Grande do Sul.

Perico-Agudelo, D. (2009). El espacio público de la ciudad: una aproximación desde el estudio de sus características micro climáticas. Cuadernos de Vivienda y Urbanismo, 2(4), 278-301.

https://revistas.javeriana.edu.co/index.php/ cvyu/article/view/5519

Pozueta, J. (2008). El espacio público en la rehabilitación/regeneración urbana. Revista de urbanismo, (18)

Rainero, L., Rodihou, M., \& Pérez, S. (2006). Herramientas para la promoción de ciudades seguras desde la perspectiva de género. CICSA, AECI, UNIFEM.

https://huairou.org/old-file/wp-content/ uploads/2016/06/CARATULAHERRAMIENTAS.pdf

Rangel, M. (2002). Los cien del espacio público para la vida sociocultural urbana. Universidad de Los Andes.

http://www.saber.ula.ve/bitstream/handle/123456789/39797/Rangel_2002.pdf;jsessionid =B99966E0FA8623E911DFB 8DA4A652AE9? sequence $=1$

Rojas Eraso, A. M. (1998). El espacio público en la ciudad colombiana: un modelo para armar. Bitácora urbano territorial, 1(2), 48-56

https://revistas.unal.edu.co/index.php/ bitacora/article/view/18841

Sato, A. (2012). Lo público del espacio. ARQ, (81), 17-19.

https://dx.doi.org/10.4067/S071769962012000200003

Serra, J. (2002). Elementos urbanos. Mobiliario y microarquitectura. Gustavo Gili.

Tricart, J., \& Killian, J. (1982). La ecografía y la ordenación del medio natural. Anagrama. h t t p s : / / d d d . u a b . c a t / p u b / dag/02121573n3/02121573n3p209.pdf

United Nations Centre for Human Settlement (UNCH). (1996). Cities as solution in an urbanizing world. Earths Can Publication.

Whyte, W. (1980). The social life of small urban spaces. Project for Public Spaces. https://www.informalscience.org/sites/ default/files/VSA-a0a1v6-a 5730.pd 

(1) Portada: Las bovedadas de Bramante.

Fotografía: Luis Alberto Martínez Camacho (2021) CC BY-NC

\section{(ब) (1) (\$)}

(A) Orientación editorial

\section{Enfoque y alcance}

La Revista de Arquitectura (Bogotá) ( (ISSN 1657-0308 Impresa y E-ISSN 2357-626X en línea) es una publicación científica seriada de acceso abierto, arbitrada mediante revisión por pares (doble ciego) e indexada, en donde se publican resultados de investigación originales e inéditos.

Está dirigida a la comunidad académica y profesional de las áreas afines a la disciplina. Es editada por la Facultad de Diseño y el Centro de Investigaciones (CIFAR) de la Universidad Católica de Colombia en Bogotá (Colombia).

La principal área científica a la que se adscribe la Revista de Arquitectura (Bogotá) según la OCDE es:

Gran área: 6. Humanidades

Área: 6.D. Arte

Disciplina: 6D07. Arquitectura y Urbanismo

También se publican artículos de las disciplinas como 2A02, Ingeniería arquitectónica; 5C03, Estudios urbanos (planificación y desarrollo); 6D07, Diseño.

Los objetivos de la Revista de Arquitectura (Bogotá) son:

- Promover la divulgación y difusión del conocimiento generado a nivel local, nacional e internacional

- Conformar un espacio para la construcción de comunidades académicas y la discusión en torno a las secciones definidas.

- Fomentar la diversidad institucional y geográfica de los autores que participan en la publicación.

- Potenciar la discusión de experiencias e intercambios científicos entre investigadores y profesionales.

- Contribuir a la visión integral de la arquitectura, por medio de la concurrencia y articulación de las secciones mediante la publicación de artículos de calidad.

- Publicar artículos originales e inéditos que han pasado por revisión de pares, para asegurar que se cumplen las normas éticas, de calidad, validez científica, editorial e investigativa.

- Fomentar la divulgación de las investigaciones y actividades desarrolladas en la Universidad Católica de Colombia.
Palabras clave de la Revista de Arquitectura (Bogotá): arquitectura, diseño, educación arquitectónica, proyecto y construcción, urbanismo.

Idiomas de publicación: español, inglés, portugués y francés. Título abreviado: Rev. Arquit.

Titulo corto: RevArq

\section{Políticas de sección}

La revista se estructura en tres secciones correspondientes a las líneas de investigación activas y aprobadas por la institución, y dos complementarias, que presentan dinámicas propias de la Facultad de Diseño y las publicaciones relacionadas con la disciplina.

Cultura y espacio urbano. En esta sección se publican los artículos que se refieren a fenómenos sociales en relación con el espacio urbano, atendiendo aspectos de la historia, el patrimonio cultural y físico, y la estructura formal de las ciudades y el territorio.

Proyecto arquitectónico y urbano. En esta sección se presentan artículos sobre el concepto de proyecto, entendido como elemento que define y orienta las condiciones proyectuales que devienen en los hechos arquitectónicos o urbanos, y la forma como estos se convierten en un proceso de investigación y nuevo de conocimiento. También se presentan proyectos que sean resultados de investigación, los cuales se validan por medio de la ejecución y transformación en obra construida del proceso investigativo. También se contempla la publicación de investigaciones relacionadas con la pedagogía y didáctica de la arquitectura, el urbanismo y el diseño.

Tecnología, medioambiente y sostenibilidad. En esta sección se presentan artículos acerca de sistemas estructurales, materiales y procesos constructivos, medioambiente y gestión, relacionados con los entornos social-cultural, ecológico y económico.

Desde la Facultad. En esta sección se publican artículos generados en la Facultad de Diseño, relacionados con las actividades de docencia, extensión, formación en investigación o internacionalización, las cuales son reflejo de la dinámica y de las actividades realizadas por docentes, estudiantes y egresados; esta sección no puede superar el $20 \%$ del contenido.

Textos. En esta sección se publican reseñas, traducciones y memorias de eventos relacionados con las publicaciones en Arquitectura y Urbanismo.
A Frecuencia de publicación

Desde 1999 y hasta el 2015, la Revista de Arquitectura (Bogotá) publicó un volumen al año, a partir del 2016 se publicarán dos números por año en periodo anticipado, enero-junio y julio-diciembre, pero también maneja la publicación anticipada en línea de los artículos aceptados (versión Post-print del autor).

La Revista de Arquitectura (Bogotá) se divulga mediante versiones digitales (PDF, HTML, EPUB, XML) e impresascon un tiraje de 700 ejemplares, los tiempos de producción de estas versiones dependerán de los cronogramas establecidos por la editorial.

Los tiempos de recepción-revisión-aceptación pueden tardar entre seis y doce meses dependiendo del flujo editorial de cada sección y del proceso de revisión y edición adelantado.

Con el usuario y contraseña asignados, los autores pueden ingresar a la plataforma de gestión editorial y verificar el estado de revisión, edición o publicación del artículo.
A Canje

La Revista de Arquitectura (Bogotá) está interesada en establecer canje con publicaciones académicas, profesionales o científicas del área de Arquitectura y Urbanismo, como medio de reconocimiento y discusión de la producción científica en el campo de acción de la publicación.

Mecanismo

Para establecer canje por favor descargar, diligenciar y enviar el formato: RevArq FP20 Canjes

Universidad Católica de Colombia (2021,
junio-diciembre). Revista de
Arquitectura (Bogotá), 23(2),
I-132. Doi: 10.14718
ISSN: I657-0308
E-ISSN: 2357-626X
Especificaciones:
Formato: $34 \times 24 \mathrm{~cm}$
Papel: Mate II5 g
Tintas: Negro y policromía

A Contacto

Dirección postal:

Avenida Caracas N ${ }^{0} \cdot 46-72$ Universidad Católica de Colombia Bogotá D. C., Colombia Código postal: 111311

Facultad de Diseño Centro de Investigaciones (CIFAR) Sede El Claustro. Bloque "L", 4 piso Diag. 46A N ${ }^{0 .} 15 b-10$ Editor, Arq. César Eligio-Triana

Teléfonos:

+57 (1) $3277300-3277333$

Ext. $3109 ; 3112$ o 5146
Fax: +57 (1) 2858895

Correo electrónico:

revistadearquitectura@ucatolica.edu.co cifar@ucatolica.edu.co

Página WEB:

www.ucatolica.edu.co

Vínculo Revistas científicas

http://publicaciones.ucatolica.edu.co revistas-cientificas

https://revistadearquitectura.ucatolica.edu.co/ 
